\title{
Biological activities and chemical composition of solvent extracts of Stoechospermum marginatum (C. Agardh)
}

\author{
Akbar Esmaeili ${ }^{\bowtie}$ and Marjan Khakpoor ${ }^{2}$ \\ 'Department of Chemical Engineering, North Tehran Branch; ²Department of Marine Chemistry, Science and Research Branch, Islamic Azad \\ University, Tehran, Iran
}

The objective of this study was to evaluate the chemical composition $\mathrm{CH} 3 \mathrm{OH}-\mathrm{CH} 2 \mathrm{Cl} 2$ (1:1) extract and biological activities of various extracts derived from the aerial parts of the brown marine alga Stoechospermum marginatum (C. Agardh). Gas chromatography (GC) and gas chromatography-mass spectroscopy (GC-MS) were used to analyze the composition of the essential oil. Total phenolics assay demonstrated a high value in hexane extract (HE), with a lower value for chloroform extract (CE), and the lowest value for methanol extract (ME). DPPH (2,2-diphenyl-1-picrylhydrazyl) assay showed that extracts of $S$. marginatum possess radical scavenging activity (RSA). Tests of the antioxidant property of the extracts revealed both electron and hydrogen transfer mechanisms. The antibacterial activity of the $M E, C E$, and $H E$ as well as an ethanol extract was estimated against seven Gram-positive and Gram-negative bacteria. The ethanol extract showed the highest antibacterial activity, and the HE showed the lowest.

Key words: Stoechospermum marginatum, antioxidant activity, antibacterial activity, extract, brown seaweed

Received: 25 February, 2012; revised: 04 October, 2012; accepted: 29 October, 2012; available on-line: 16 November, 2012

\section{INTRODUCTION}

Marine organisms are a rich source of structurally new and biologically active metabolites. In recent years, there have been many reports of macroalgae-derived compounds that posses a broad range of biological functions, such as antibiotic, antiviral, antioxidant, antifouling, anti-inflammatory, cytotoxic, and antimitotic activities (Vairappan et al., 2001; Smit, 2004; Thirumaran et al., 2006). Bioactive components have been revealed in many marine algae (Yang et al., 2006; Venkateswarlu et al., 2007; Oh et al., 2008). Among the algal substances that have displayed this kind of activity, amino acids, terpenoids, phlorotannins, steroids, phenolic compounds, fatty acids, and acrylic acid are of note (Yamamoto et al.,1984; Ely et al. 2004; Taskin et al., 2007). Marine algal compounds are predominantly found with diverse functional groups and hence have different properties. They have been reported to possess antioxidant activity and thus have been widely investigated. The role of algae in human health has been demonstrated by studies confirming their antioxidant and antimicrobial activities, and as a result algal products are in demand by consumers. Marine algae are also well known as rich sources of bioactive natural products (Iliopoulere et al., 2002; Metzger et al., 2002). Additionally, marine algae have been shown to be effective in prevention of cancer as well as cardiovascular and degenerative diseases (Lordan et al., 2011).

Oxidation is a natural process occurring in organisms in the production of energy to fuel biological cycles. However, on uncontrolled production of oxygen-derived free radicals is involved in the onset of such diseases as arthritis, atherosclerosis, and cancer as well as in many aging-related degenerative diseases (Halliwell \& Gutteridge, 1984; Shahidi et al., 1992). In recent years, numerous drug resistance mechanisms in human pathogenic microorganisms have developed due to indiscriminate use of commercial antimicrobial drugs commonly used in the treatment of infectious diseases. Therefore, novel compounds encompassing both antioxidant and antimicrobial activities would be of great commercial value to the pharmaceutical industries today. An important aspect of investigation into the antioxidant and antibacterial capabilities of substances includes determination of their radical scavenging activity (RSA) (Sohrabipour \& Rabii, 1990).

The objective of this study was primarily to analyze the chemical composition of $\mathrm{CH}_{3} \mathrm{OH}-\mathrm{CH}_{2} \mathrm{Cl}_{2}$ (1:1) extract of $S$. marginatum, a brown seaweed collected from the waters of Gwadar Bay, Chah Bahar, and Sistan and Balochistan Province, Iran, using GC and GC-MS to determine its chemotypes. The secondary objective was to investigate the antibacterial and antioxidant activities of methanol, chloroform, hexane, and ethanol extracts of this promising alga.

\section{MATERIALS AND METHODS}

Plant material. S. marginatum (C. Agardh) was collected from the waters of Gwadar Bay, Chah Bahar, and Sistan and Balochistan Province, Iran, at a depth of 0.51 $\mathrm{m}$ in November, 2011. Voucher specimens were deposited at the Research Institute of Forests and Rangelands Herbarium, Tehran, Iran (Esmaeili \& Amiri, 2011). The harvested seaweed was rinsed repeatedly in tap water to clean sand, dirt, and other particles from it. Using a procedure reported in similar studies the washed alga was then dried in the sun for 5 days (Gupta et al., 2001). The resulting dry biomass was milled to a particle size averaging 2-5 $\mathrm{mm}$. The algal powder was divided into four $90-\mathrm{g}$ portions and extracted with, respectivity, $\mathrm{CH}_{3} \mathrm{OH}-$ $\mathrm{CH}_{2} \mathrm{Cl}_{2}$ (1:1), methanol, chloroform, ethanol, or hexane for $24 \mathrm{~h}$. After $24 \mathrm{~h}$, each solvent extract was filtered

e-mail: akbaresmaeili@yahoo.com

Abbreviations: CE, chloroform extract; GC, Gas chromatography; GC-MS, gas chromatography-mass spectroscopy; HE, hexane extract; $M E$, methanol extract; RIs, retention indices; RSA, radical scavenging activity. 
through Whatman filter paper (No. 1) and then concentrated in a vacuum for $3 \mathrm{~h}$ at $40^{\circ} \mathrm{C}$ using a rotary evaporator (Buchi, Flawil, Switzerland) to obtain a semisolid extract, which was then weighed.

Gas chromatography analysis. GC analysis was carried out using a Shimadzu 15A gas chromatograph equipped with a split/splitless injector $\left(250^{\circ} \mathrm{C}\right)$ and a flame ionization detector $\left(250^{\circ} \mathrm{C}\right)$. The carrier gas used was nitrogen $(1 \mathrm{ml} / \mathrm{min})$, and DB-5 (50 $\mathrm{m} \times 0.2 \mathrm{~mm}$, $0.32 \mu \mathrm{m}$ film thickness) was used for as capillary column. The column temperature was kept at $60^{\circ} \mathrm{C}$ for 3 min and then heated to $220^{\circ} \mathrm{C}$ at a rate of $5^{\circ} \mathrm{C} / \mathrm{min}$ and kept content at $220^{\circ} \mathrm{C}$ for $5 \mathrm{~min}$. The relative percentage of all compounds was calculated from peak areas using a Shimadzu CR4A Chromatopac without the use of correction factors.

Gas chromatography-mass spectroscopy analysis. GC-MS analysis was accomplished using a Hewlett Packard 5973 with an HP-5MS column (30 $\mathrm{m} \times 0.25$ $\mathrm{mm}$, film thickness $0.25 \mu \mathrm{m})$. The column temperature was as above. The flow rate of helium as a carrier gas was $1 \mathrm{ml} / \mathrm{min}$. Mass spectroscopy readings were taken at $70 \mathrm{eV}$. The MSD was operated under $70 \mathrm{eV}$, with a scan range of 41-300 amu. The MSD was tuned every day using perfluorotributylamine as a tuning standard.

Qualitative and quantitative analyses. GC identification of most constituents was made by comparing retention indices (RIs) with those found in the literature or with RIs of authentic compound samples in our facilities. Determination of the RIs was made in relation to a homologous series of $n$-alkanes $\left(\mathrm{C}_{8}-\mathrm{C}_{28}\right)$ under identical conditions of operation. Comparison of the mass spectra of constituents on both columns with mass spectra stored in the NIST 02 and Wiley 275 libraries or with mass spectra recorded in the literature or in our own library served as an additional identification. Relative concentrations of the components were calculated based on GC peak areas with no correction factors invoked (Mass Spectrometry Data Centre, 1991; Joulain \& König, 1998; Adams, 2007).

\section{Antimicrobial assay}

Microorganisms. Pure cultures of Staphylococcus aureus (PTCC1113), Staphylococcus epidermidis (PTCC1349), Bacillus anthracis (PTCC1036), Escherichia coli (PTCC1330), and Pseudomonas aeruginosa (PTCC1310) were used as test organisms and the bioassay was done using an agar plate diffusion test.

Preparation of inocula. After incubating the nutrient agar slant of each test organism for $24 \mathrm{~h}$, a loop full of the microorganism was inoculated in a nutrient broth with $\mathrm{pH} 7.4$ so as to activate the bacterial strains. The broths were incubated at $37^{\circ} \mathrm{C}$ for $24 \mathrm{~h}$ to allow the microorganisms to grow. A separate uninoculated nutrient broth was maintained as a control.

Antibacterial activity test. Antibacterial activity was assayed using the agar well diffusion test technique. Müller Hinton agar (MHA) was prepared at $\mathrm{pH} 7.4$ and then sterilized by autoclaving at $121^{\circ} \mathrm{C}$ for $15 \mathrm{~min}$, after which $20 \mathrm{ml}$ of the sterilized medium was poured into a sterilized Petri dish and allowed to solidify at room temperature. A sterile cotton swab was used for spreading each test microorganism from the inoculated broth evenly onto an MHA plate. The plates were allowed to sit for a few minutes to allow complete absorption of the inocula. In each plate a $5-\mathrm{mm}$ diameter well was made at the center using an appropriately sized sterilized cork borer. One hundred microliter of each extract (HE, ME, and $\mathrm{CE}$ ) was added to the wells on the MHA plates and allowed to diffuse at room temperature for $30 \mathrm{~min}$. No extract was added to the control MHA plate, which was used for comparing the obtained results to detect any contamination. The plates were incubated at $37^{\circ} \mathrm{C}$ for $24 \mathrm{~h}$. After incubation a clear zone was observed around the well, which was evidence of the presence of antibacterially active compounds in the extracts. The diameter of the zone of inhibition was measured in millimeters.

For comparing the antibacterial activity of the isolated extracts with the therapeutic action of a number of known, broad spectrum antibiotics. The zone exhibited by extracts was compared to the inhibition zone produced by the standard antibiotics (Seenivasan et al., 2010; Esmaeili \& Amiri, 2011; Esmaeili \& Khodadadi, 2012).

\section{Antioxidant activity}

Chemicals. Butylated hydroxytoluene (BHT) and 2,2-diphenyl-1-picrylhydrazyl (DPPH) were purchased from Sigma (Sigma, Aldrich GmbH, Sternheim, Germany). Folin-Ciocalteau's phenol reagent, sodium bicarbonate, ethanol, chloroform, methanol, and the other chemicals and reagents employed in the study were purchased from Merck (Darmstadt, Germany). All other unlabeled chemicals and reagents used were of analytical grade.

DPPH assay. Kinetic data suggest that an electron transfer mechanism rather than the more commonly assumed hydrogen atom transfer reaction may be active in the DPPH assay. A published DPPH RSA assay method with minor modifications was employed to evaluate the RSA of the ME, HE, and CE of $S$. marginatum. In this assay, $10 \mathrm{mg} / \mathrm{ml}$ stock solutions were prepared by dissolving the extracts and the synthetic antioxidant BHT in methanol. The solutions were diluted to concentrations ranging from 1 until $5 \times 10^{-6} \mathrm{mg} / \mathrm{ml} ; 2 \mathrm{ml}$ of each diluted solution was then mixed with $2 \mathrm{ml}$ of $80 \mathrm{mg}$ / $\mathrm{ml}$ DPPH methanol, chloroform, or hexane solution and left in the dark at room temperature for $30 \mathrm{~min}$. Then absorbance of each solution was recorded on a spectrometer at $517 \mathrm{~nm}$ using a blank containing the same concentration of BHT or extract without DPPH. Percentage of inhibition of free radicals by DPPH was calculated as follows:

$I \%=\frac{A_{\text {blank }}-A_{\text {sample }}}{A_{\text {blank }}} \times 100$

where $I \%$ is the inhibition percentage, $A_{\text {blank }}$ is the absorbance of the control reaction, and $A_{\text {sample }}$ is the absorbance of the test compound. Inhibition percentages were plotted against the sample concentrations to calculate the concentration providing 50\% inhibition $\left(\mathrm{IC}_{50}\right)$. Each test was performed 3 times; the $\mathrm{IC}_{50}$ value was represented as means \pm standard deviation.

Determination of total phenolic compounds. Total phenolic constituents in the methanol extract of S. marginatum were determined using a published method employing Folin-Ciocalteau's reagent, with gallic acid as the standard (Esmaeili \& Khodadadi, 2012). Extract solutions (ME, HE, and $\mathrm{CE}$ ) containing $0.1 \mathrm{ml}$ of each extract were placed in volumetric flasks; $46 \mathrm{ml}$ of distilled water and $1 \mathrm{ml}$ Folin-Ciocalteu's were added, and the flasks were shaken thoroughly. After $3 \mathrm{~min}, 3 \mathrm{ml}$ of a solution of $7 \% \mathrm{Na}_{2} \mathrm{CO}_{3}$ was added to each flask, and the mixture was allowed to stand for $2 \mathrm{~h}$ with intermittent shaking. Absorbance was measured at $765 \mathrm{~nm}$. The same procedure was repeated for all standard gallic acid 
solutions (0-1000 mg/0.1 ml), and a standard curve was obtained using the following equation:

absorbance $=0.0012 \times$ gallic acid $(\mathrm{mg})+0.0033$

Scavenging of hydrogen peroxide. The ability of the extracts to scavenge hydrogen peroxide was determined using the method described in a recently published paper (Esmaeili et al., 2009). A solution of hydrogen peroxide $(40 \mathrm{mM})$ was prepared in a phosphate buffer solution ( $\mathrm{pH}$ 6.6). $\mathrm{CE}, \mathrm{HE}$, and $\mathrm{ME}$ extracts in distilled water were added to a hydrogen peroxide solution $(0.6 \mathrm{ml}, 40 \mathrm{mM})$. The absorbance of hydrogen peroxide at $230 \mathrm{~nm}$ was determined after 10 minutes and compared against a blank solution containing phosphate buffer without hydrogen peroxide. The percentage of hydrogen peroxide scavenging by the extracts and standard compounds were calculated as follows:

$\%$ scavenged $\mathrm{H}_{2} \mathrm{O}_{2}=\frac{\mathrm{A}_{0}-\mathrm{A}_{1}}{\mathrm{~A}_{0}} \times 100$

where $A_{0}$ is the absorbance of the control and $A_{1}$ is the absorbance in the presence of the extract or standard (Esmaeili et al., 2009).

\section{RESULTS}

\section{Chemical components identified}

The chemical composition of the $\mathrm{CH}_{3} \mathrm{OH}-\mathrm{CH}_{2} \mathrm{Cl}_{2}(1: 1)$ extract of $S$. marginatum is given in Table 1 . Twelve of the compounds identified represented $98.0 \%$ of the total composition of the oil. The major compounds identified were 4-epi-abietol (42.1\%) and palustrol (14.5\%). Another notable constituent was octane (13.2\%). Diterpenes comprised the most abundant components of the oil $(50.2 \%)$. Two sesquiterpene hydrocarbons (16.6\%) and hydrocarbon aliphatic compounds (including acidic compounds and nonacidic compounds) (24.4\%) were also found.

\section{Amount of DPPH}

The antioxidant activity of the CE, HE, and ME of S. marginatum was investigated using $\mathrm{DPPH}$ assay. The antioxidant activity of the extract compounds was measured in terms of hydrogen donating or RSA, using the

Table 1. Chemical components of the essential oil of Stoechospermum marginatum

\begin{tabular}{llll}
\hline No. & Compound & R.I & $\%$ \\
\hline 1 & Octane & 800 & 13.2 \\
2 & Nonanone & 1091 & 1.0 \\
3 & Hexadecanoic acide & 1970 & 1.8 \\
4 & Sclarene & 1967 & 1.2 \\
5 & Accidol acetate & 1970 & 2.1 \\
6 & Manoyl oxide & 1989 & 5.1 \\
7 & Manool & 2056 & 1.8 \\
8 & Ethyl octadecanoate & 2194 & 1.5 \\
9 & Docosene & 2195 & 6.9 \\
10 & 2-Keto-Manoyl oxide & 2208 & 6.8 \\
11 & Palustrol & 2314 & 14.5 \\
12 & 4-epi-abietol & 2341 & 42.1 \\
Total & & & 98.0 \\
\hline
\end{tabular}

stable radical DPPH. ME, CE, and $\mathrm{HE}$ were able to reduce DPPH to yellow-colored diphenylpicrylhydrazine with $\mathrm{IC}_{50}$ values of $0.064 \pm 0.0012 \mathrm{mg} / \mathrm{ml}$ for $\mathrm{ME}$, $0.15 \pm 0.002 \mathrm{mg} / \mathrm{ml}$ for $\mathrm{HE}$, and $0.21 \pm 0.06 \mathrm{mg} / \mathrm{ml}$ for $\mathrm{CE}$. The concentration of the positive control BHT required to scavenge $50 \%$ of the free radical $\left(\mathrm{IC}_{50}\right)$ was $0.13 \pm 0.06 \mathrm{mg} / \mathrm{ml}$.

\section{Total phenol content}

The total phenolic content of the S. marginatum extracts was measured using Folin-Ciocalteau's reagent. The results were expressed as gallic acid. Our investigation found that the values of $S$. marginatum extracts $(\mathrm{ME}$, $\mathrm{HE}$, and $\mathrm{CE}$ ) were $0.041 \pm 0.001 \mathrm{mg} / \mathrm{ml}, 0.018 \pm 0.005$ $\mathrm{mg} / \mathrm{ml}$, and $0.02 \pm 0.003 \mathrm{mg} / \mathrm{ml}$, respectively. The $\mathrm{IC}_{50}$ value for gallic acid was $0.13 \pm 0.065 \mathrm{mg} / \mathrm{ml}$. The highest total phenolic content was found in the ME and the lowest in the HE.

\section{Hydrogen peroxide scavenging}

Although hydrogen peroxide itself is not very reactive, it can sometimes cause cytotoxicity by giving rise to hydroxyl radicals in the cell. Thus, removing $\mathrm{H}_{2} \mathrm{O}_{2}$ from food systems is important (Ebrahimzadeh et al., 2009). Scavenging of $\mathrm{H}_{2} \mathrm{O}_{2}$ by extracts may be attributed to their phenolics, which can donate electrons to $\mathrm{H}_{2} \mathrm{O}_{2}$, thus neutralizing it to water (Esmaeili \& Khodadadi, 2012). The ability of the extracts to effectively scavenge hydrogen peroxide was determined according to the method used by Ruch, in which the extracts are compared with quercetin as the standard (Ebrahimzadeh et al., 2009). The extracts were capable of scavenging hydrogen peroxide in a concentration-dependent manner and demonstrated moderately good scavenging activity. Our investigation found that the $\mathrm{IC}_{50}$ values for the $S$. marginatum extracts (ME, HE, and CE) were $4.21 \pm 0.14 \mathrm{mg} /$ $\mathrm{ml}, 0.27 \pm 0.0 .01 \mathrm{mg} / \mathrm{ml}$, and $0.29 \pm 0.11$, respectively. The $\mathrm{IC}_{50}$ value for ascorbic acid was $4.45 \pm 0.05 \mathrm{mg} / \mathrm{ml}$. The effect was significant in some tests but further investigation of individual compounds and their antioxidant activities in vivo and in different antioxidant mechanisms is needed.

\section{Antibacterial activity}

The antibacterial tests were carried out at the Department of Biological Science, North Tehran Branch, Islamic Azad University, Tehran, Iran, using the following microorganisms: Staphylococcus aureus PTCC 1113 and Staphylococcus epidermidis PTCC 1349, (Gram-positive bacteria), and Bacillus anthracis PTCC 1036, Escherichia coli PTCC 1330, and Pseudomonas aeruginosa PTCC 1310 (Gram-negative bacteria), identified by the Iranian Research Organization for Science \& Technology (Table 2).

In the study, we investigate ethanol extract only in microorganisms test. The microorganisms were obtained from enrichment culture in $1 \mathrm{ml}$ of Müller-Hinton agar medium. Figure 1 shows the results of the investigation of the antibacterial action of the ethanol extract, ME, $\mathrm{HE}$, and $\mathrm{CE}$ from the aerial parts of $S$. marginatum using the agar well diffusion test technique, with comparative growth inhibitory zones.

\section{DISCUSSION}

In this study, 12 compounds were identified in the $\mathrm{CH}_{3} \mathrm{OH}-\mathrm{CH}_{2} \mathrm{Cl}_{2}$ extract of $\mathrm{S}$. marginatum, with diterpenes comprising over $50 \%$ of the compounds found. In 
Table 2. Antibacterial activity of different extracts of Stoechospermum marginatum ${ }^{\text {a }}$

\begin{tabular}{|c|c|c|c|c|c|c|c|}
\hline Bacterial Species & Gram +/- & $M E^{b}$ & $\mathrm{HE}^{\mathrm{c}}$ & $C E^{d}$ & Ethanol extract & Ciprofloxacin & Erythromycin \\
\hline $\begin{array}{l}\text { Staphylococcus aureus } \\
\text { (PTCC 1113) }\end{array}$ & + & - & - & 15 & 20 & & 28 \\
\hline $\begin{array}{l}\text { Staphylococcus epidermidis } \\
\text { (PTCC 1349) }\end{array}$ & + & 10 & 18 & 17 & 15 & & 25 \\
\hline $\begin{array}{l}\text { Bacillus anthracis } \\
\text { (PTCC 1036) }\end{array}$ & + & 15 & - & - & 13 & & 20 \\
\hline $\begin{array}{l}\text { Escherichia coli } \\
\text { (PTCC 1330) }\end{array}$ & - & - & - & 17 & 12 & 34 & \\
\hline $\begin{array}{l}\text { Pseudomonas aeruginosa } \\
\text { (PTCC 1310) }\end{array}$ & - & 14 & 10 & 17 & 19 & 35 & \\
\hline
\end{tabular}

${ }^{a}$ Agar disc diffusion method: Diameter of inhibition zone including disk diameter of $100 \mathrm{~mm}$; ${ }^{\mathrm{b}} \mathrm{ME}=\mathrm{methanol}$ extract; $\mathrm{cHE}=\mathrm{hexane}$ extract; ${ }^{\mathrm{d}} \mathrm{CE}=$ chloroform extract

on other study, Iranian researchers isolated two spatane diterpenes, 5(R),16(S)-diacetoxyspata-13,17-diene and 5(R),16(S)-dihydroxyspata-13,17-diene from S. marginatum (Rosa et al., 1991). A comparison of the analysis of the extracts of $S$. marginatum in that study with our result does shows many similar compounds. In previous studies, the essential oils of various brown algae have been investigated, isolating 8 compounds from Dictyota dichotoma, 12 compounds from $D$. dichotoma, 4 from Petalonia fascia, 4 from Scytosiphon lomentaria, and 14 compounds for Colpomenia sinuosa, accounting for $58.41 \%, 83.53 \%$, $91.71 \%, 87.89 \%$, and $74.17 \%$ of the total composition of the essential oils, respectively (Ozdemir et al., 2006). The aliphatic hydrocarbons heptadecane and hexadecane have also been reported as common major volatile components in seaweeds (Stirk et al., 2007).

$\mathrm{ME}, \mathrm{HE}$, and $\mathrm{CE}$ reduced the stable violet $\mathrm{DPPH}$ radical to the yellow diphenylpicrylhydrazine. The con-

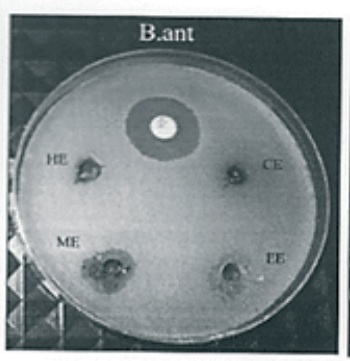

a

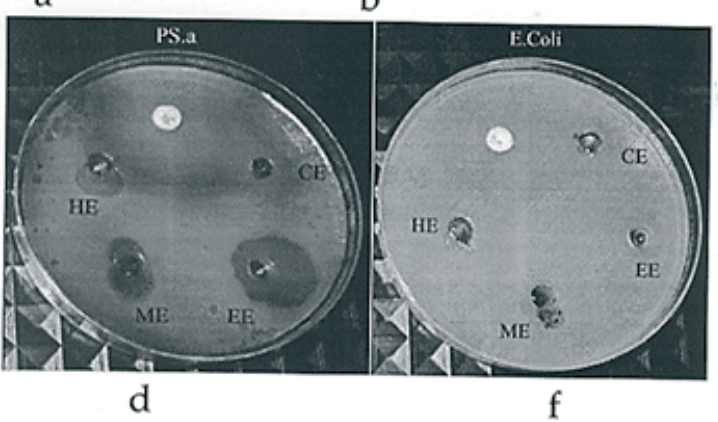

Figure 1. Diffusion disk antibacterial test of $\mathrm{EE}, \mathrm{ME}, \mathrm{CE}$, and $\mathrm{HE}$ extracts grown in S. marginatum against five tested strains of bacteria

(a) Bacillus anthracis; (b) Staphylococcus aureus; (c) Staphylococcus epidermidis; (d) Pseudomonas aeruginosa; (f) Escherichia coli centrations of $\mathrm{ME}, \mathrm{HE}$, and $\mathrm{CE}$ needed to scavenge $50 \%$ of the free radicals were $0.064 \pm 0.0012 \mathrm{mg} / \mathrm{ml}$, $0.15 \pm 0.002 \mathrm{mg} / \mathrm{ml}$, and $0.21 \pm 0.06 \mathrm{mg} / \mathrm{ml}$, respectively. Phenolic compounds may affect the growth and metabolism of bacteria. They could have an activating or inhibiting effect on microbial growth according to their constitution and concentration (Ebrahimzadeh et al., 2008; Esmaeili et al., in press). Folin-Ciocalteau's reagent was employed to assay total phenolic compounds present in the extracts. The highest total phenolic content was found in the HE $(0.018 \pm 0.005 \mathrm{mg} / \mathrm{ml})$ and the lowest value in the ME $(0.041 \pm 0.01 \mathrm{mg} / \mathrm{ml})$. The phenolic content was high in the polar extracts. The importance of phenolic compounds as scavengers of free radicals is emphasized in a number of studies (Madsen et al., 2000). It should be noted that the volatile components still present in the nonpolar $\mathrm{ME}, \mathrm{CE}$, and $\mathrm{HE}$ could also be responsible for the antioxidant activity.

The scavenging of $\mathrm{H}_{2} \mathrm{O}_{2}$ by the extracts may be attributed to their phenolics, which can donate electrons to $\mathrm{H}_{2} \mathrm{O}_{2}$ and neutralize it to $\mathrm{H}_{2} \mathrm{O}$. The ability of the extracts to effectively scavenge hydrogen peroxide was determined according to the Ruch's method (Ebrahimzadeh et al., 2009), with quercetin employed as the standard. The extracts were capable of scavenging hydrogen peroxide in a concentration-dependent manner. The HE extract showed moderately good scavenging activity, with an $\mathrm{IC}_{50}$ value of $0.27 \pm 0.0 .01 \mathrm{mg} / \mathrm{ml}$, while the $\mathrm{IC}_{50}$ value for ascorbic acid was $4.45 \pm 0.05 \mathrm{mg} / \mathrm{ml}$.

When we investigated the antibacterial activity of the ethanol extract, $\mathrm{ME}, \mathrm{CE}$, and $\mathrm{HE}$, we found that the $\mathrm{CE}$ and $\mathrm{EE}$ were the most effective in inhibiting bacterial activity. In an agar plate diffusion test, the ethanol extract, $\mathrm{ME}, \mathrm{CE}$, and $\mathrm{HE}$ of S. marginatum showed the highest antibacterial activity of $S$. marginatum (15, 
10, 17, and $18 \mathrm{~mm}$, respectively) and P. aeruginosa (19, 14,17 , and $10 \mathrm{~mm}$, respectively). The EE of $S$. marginatum strongly inhibited the growth of $S$. aureus and $P$. aeruginosa. The $\mathrm{CE}$ showed the highest antibacterial activity against E. coli and was second to the EE in effectiveness against $P$. aeruginosa. The $\mathrm{HE}$ and $\mathrm{CE}$ showed the highest activity against $S$. epidermidis. Among all the test microorganisms, the lowest results were exhibited on $B$. anthracis, with the ME being the most effective (Table 2). These results indicate that the extracts contained different antibacterial components and may reflect the variety of secondary metabolites in the extracts (Ozdemir et al., 2004). Antimicrobial activities of essential oils could be attributed to camphor and it derivatives such as borneol. The synergistic effects of these chemicals with each other and the minor constituents of the essential oil should be taken into consideration. Although the mechanism of the antibacterial activity of the terpenoids making up essential oils is not fully understood, it is thought to involve membrane disruption by the lipophilic compounds (Cowan et al., 1999).

Inhibited formation of hydroperoxide is related to the presence of phenolic nuclei in essential oils and their extracts (Farag et al., 1989). Phenolic compounds account for the antioxidative effectiveness of natural sources. Among the extracts, the ME exhibited the strongest and broadest antioxidant activity.

\section{CONCLUSION}

In our work we used GC and GC-MS to study the chemical composition of the $\mathrm{CH}_{3} \mathrm{OH}-\mathrm{CH}_{2} \mathrm{Cl}_{2}$ (1:1) extract derived from the aerial parts of $S$. marginatum (C. Agardh). We identified 12 constituents, of which 4-epi-abietol (42.1\%) and palustrol $(14.5 \%)$ were the major components. The constituents identified represented $98.0 \%$ of the total oil. Diterpenes comprised more than half of the oil's components (50.2\%). Antibacterial effectiveness of various extracts of $S$. marginatum was also investigated. Antioxidant activity was investigated by assaying total phenolic content, scavenging activity of $\mathrm{H}_{2} \mathrm{O}_{2}$, and DPPH. In these tests the extracts of $S$. marginatum demonstrated antioxidant activity and potential usefulness in this arena. The antibacterial activity of the ME, $\mathrm{CE}, \mathrm{EE}$, and $\mathrm{HE}$ against Gram-positive and Gramnegative bacteria was also investigated. The strongest antibacterial activity was observed in the EE and CE of S. marginatum.

\section{REFERENCES}

Adams RP (2007) Identification of Essential Oil Components by Gas Chromatography/mass Sspectroscopy. 4th edn. Allured Publishing, Carol Stream, IL.

Cowan MM (1999) Plant products as anti-microbial agents. Clin Microbiol Rev 12: 564-82.

Ebrahimzadeh MA, Hosseinimehr SJ, Hamidinia A, Jafari M (2008) Antioxidant and free radical scavenging activity of Feijoa sallowiana fruits peel and leaves. Pharmacologyonline 1: 7-14.

Ebrahimzadeh MA, Nabavi SF, Nabavi SM (2009) Antioxidant activities of methanol extract of Sambucus ebulus L. flower. Pak J Biol Sci 12: 447-450.

Ely R, Supriya T, Naik CG (2004) Antimicrobial activity of marine organisms collected off the coast of South East India. J Exp Mar Biol Ecol 309: 121-127.
Esmaeili A, Amiri H (2011) The in vitro antioxidant and antibacterial activities of Tanacetum pinnatum boiss. grown in Iran. Bulgarian Chem Com 43: 267-271.

Esmaeili A, Rashidi B, Rezazadeh S (2012) Biological activities of various extract and chemical composition of Trigonella monantha C. A. Mey. subsp. monantha grown in Iran. Iran J Pharm Res (in press).

Esmaeili A, Tavassoli A, Ebrahimzadeh MA (2009) Antioxidant activity and free radical scavenging activity of Salvia glutinosa growing in Iran. Pharmacologyonline 2: 109-116.

Esmaeili A, Khodadadi A (2012) Antioxidant activity of a solution of thymol in ethanol. Zahedan J Res Med Sci 14: 14-18.

Farag B, El-Baroti (1989) Antioxidant activity of some spice essential oils on linoleic acid oxidation in aqueous media. Am Oil Chem Soc 66: 792-99.

Gupta VK, Shrivastava AK, Jain N (2001) Biosorption of chromium(VI) from aqueous solutions by green algae Spirogyra Species. Wat Res 35: 4079-4085.

Halliwell B, Gutteridge JMC (1990) Role of free radicals and catalytic metal ions in human disease: an overview. Methods in Ensymol 186: $1-85$.

Iliopoulere D, Agias C, Harvala C, Roussis V (2002) C15 acetogenins from the red alga Laurencia obtuse. Phytochem 59: 111-116.

Joulain D, König WA (1998) The atlas of spectral data of sesquiterpene bydrocarbons. E. B.-Verlag, Hamburg.

Lordan S, Ross RP, Stanton C (2011) Marine bioactives as functional food ingredients: potential to reduce the incidence of chronic diseases. Marine Drugs 9: 1056-1100.

Madsen HL, Andersen CM, Jorgensen LV, Skibsted LH (2000) Radical scavenging by dietary flavonoids: a kinetic study of antioxidant efficiencies. Eur Food Res Tech 211: 240-246.

Mass Spectrometry Data Centre (1991) Eight peak index of mass spectra. 4th edn. Unwin Brothers, Surrey.

Metzger P, Roger MN, Largean C (2002) Botryolins A and B, two tetramethylsqualene triethers from the green microalga Botryococcus braunii. Phytochem 59(8): 839-843.

Oh K, Lee G (2008) Antimicrobial activities of the bromophenols from the red alga Odonthalia corymbifera and some synthetic derivatives. Bioorganic and Medicinal Chem Lett 18: 104-108.

Ozdemir G, Karabay NU, Dalay CM, Pazarbasi B (2004) Antibacterial activity of volatile components and various extracts of Spirulina platensis. Phytother Res 18: 754-757.

Rosa SD, Iodice C, Khalaghdoust M, Oryan S, Rustaiyan A (1999) Spatane diterpenoids from the brown alga Stoechospermum marginatum (Dictyotaceae). Phytochem 51: 1009-1012.

Seenivasan R, Indu H, Archana G, Geetha S (2010) The antibacterial activity of some marine algae from south east coast of India. J Phar Res 8: 1907-1912.

Shahidi F, Janitha PK, Wanasundara PD (1992) Phenolic antioxidants. Crit Rev Food Sci Nutr 32: 67-103.

Smit AJ (2004) Medicinal and pharmaceutical uses of seaweed natural products: a review. J Appl Phycol 16: 245-262.

Sohrabipour J, Rabii R (1990) A list of marine algae of seashores of Persian Gulf Oman Sea in the Hormozgan province. Iran J Botony 8: $131-162$.

Stirk WA, Reinecke DL, Staden J (2007) Seasonal variation in antifungal, antibacterial and acetylcholinesterase activity in seven South African seaweeds. J Appl Phycol 19: 271-276.

Taskin E, Ozturk M, Taskin E, Kurt O (2007) Antibacterial activities of some marine algae from the Aegean Sea (Turkey). African J Biotech 6: 2746-2751.

Thirumaran G, Vijayabaskar P, Anantharaman P (2006) Antibacterial and antifungal activities of brown Marine macro alaga Dictyota dichotoma) from the Gulf of Mannar biosphere reserve. Environ Ecol 24S: $37-40$.

Vairappan CS, Daitoh M, Suzuki M, Abe T, Masuda M (2001) Antibacterial halogentaed metabolites from the Malaysian Laurencia species. Phytochem 58: 291-297.

Venkateswarlu G, Panchagnula K, Aditya L, Gottumukkala VS (2007) Synthesis, structural revision and biological activities of 4-chloroaurone, a metabolite of marine brown alga Spatoglossum variabile. Tetrabedron 63: 6909-6914.

Yamamoto I, Takahashi M, Tamura E, Maruyama H, Mori H (1984) Antitumor activity of edible marine algae: effect of crude fucoidan fractions prepared from edible brown seaweeds against L-1210 leukemia. Hydrobiologia 116/117: 145-148.

Yang L, Peng LS, Zhou S, (2006) Lactones from a brown alga endophytic fungus (No. ZZF36) from the South China Sea and their antimicrobial activities. Bioorganic and Med Chem Lett 16: 4205-4208. 